\title{
Atomic Control of Active Site Ensembles in Ordered Alloys to Enhance Hydrogenation Selectivity
}

\section{Anish Dasgupta}

Pennsylvania State University

\section{Hoaran He}

Pennsylvania State University

\section{Rushi Gong}

Pennsylvania State University

\section{Shun-Li Shang}

Pennsylvania State University

\section{Eric Zimmerer}

Pennsylvania State University

\section{Randall Meyer}

ExxonMobil (United States)

Zi-Kui Liu

Pennsylvania State University

\section{Michael Janik}

Pennsylvania State University

Robert Rioux ( $\square$ rmr189@psu.edu )

Pennsylvania State University https://orcid.org/0000-0002-6019-0032

\section{Article}

Keywords: Catalysis, Heterogeneous catalysis, Atomic Control, Active Site Ensembles, Ordered Alloys, Hydrogenation Selectivity

Posted Date: March 19th, 2021

DOl: https://doi.org/10.21203/rs.3.rs-311464/v1

License: (c) (1) This work is licensed under a Creative Commons Attribution 4.0 International License. Read Full License

Version of Record: A version of this preprint was published at Nature Chemistry on February 3rd, 2022. See the published version at https://doi.org/10.1038/s41557-021-00855-3. 



\section{Atomic Control of Active Site Ensembles in Ordered Alloys to Enhance Hydrogenation Selectivity}

Anish Dasgupta ${ }^{1 \dagger}$, Haoran $\mathrm{He}^{1 \dagger}$, Rushi Gong ${ }^{2}$, Shun-Li Shang ${ }^{2}$ Eric K. Zimmerer ${ }^{1}$, Randall J. Meyer $^{3}$, Zi-Kui Liu ${ }^{2}$, Michael J. Janik ${ }^{1,{ }^{*}}$ and Robert M. Rioux ${ }^{1,4,}{ }^{*}$

${ }^{1}$ Department of Chemical Engineering, The Pennsylvania State University, University Park, PA16802, USA

${ }^{2}$ Department of Materials Science and Engineering, The Pennsylvania State University, University Park, PA 16802, USA

${ }^{3}$ ExxonMobil Research and Engineering, Annandale, NJ 08801, USA

${ }^{4}$ Department of Chemistry, The Pennsylvania State University, University Park, PA 16802, USA

*Corresponding Author.rmr189@psu.edu; mjj13@psu.edu

${ }^{\dagger}$ These authors contributed equally. 


\begin{abstract}
Intermetallic compounds offer unique opportunities for atom-by-atom manipulation of catalytic ensembles through precise stoichiometric control. The $[\mathrm{Pd},(\mathrm{M}), \mathrm{Zn}] \gamma$-brass phase allows for controlled synthesis of Pd-M-Pd catalytic sites $(\mathrm{M}=\mathrm{Zn}, \mathrm{Pd}, \mathrm{Cu}, \mathrm{Ag}$ and $\mathrm{Au})$ isolated in an inert Zn matrix. These multi-atom heteronuclear active sites are catalytically distinct from Pd single atoms and fully coordinated Pd. We quantify the unexpectedly large effect of active site composition (i.e., identity of M atom in Pd-M-Pd sites) on ethylene selectivity during acetylene semi-hydrogenation. Subtle stoichiometric control demonstrates Pd-Pd-Pd sites are active for ethylene hydrogenation, whereas Pd-Zn-Pd sites show no measurable ethylene to ethane conversion. Agreement between experimental and density functional theory predicted activities and selectivities demonstrates precise control of Pd-M-Pd active site composition. The diversity and well-defined structure of intermetallics can be utilized to design active sites assembled with atomic-level precision.
\end{abstract}




\section{Introduction}

Advances in heterogeneous catalyst active site design are limited by our ability to exert atomicallyprecise synthetic control over active site ensembles. ${ }^{1}$ Tailoring the electronic and geometric structure of the active site has mainly been accomplished by carefully tuning bimetallic alloys, in which the addition of the second metal modifies the electronic and structural properties of the primary reactive metal. Development of model bimetallic catalysts has traditionally relied on vapor deposition of a second (minority) metal onto a single crystalline form of the host metal, followed by annealing treatment to form a bimetallic surface. ${ }^{2-5}$ Vapor deposition methods lead to a distribution of ensemble sizes of ill-defined geometry and composition, and large uncertainty in surface composition due to redistribution of the deposited metal between the surface and subsurface post annealing.

A more recent application of this approach, in which low loadings of a second metal are physically deposited on a well-defined surface of a second metal, has led to a class of "single atom alloy" (SAAs) catalysts. ${ }^{6-8}$ As the name implies, SAAs may possess well-defined active sites consisting of isolated metal atoms in an inert or less active host metal. Sykes and co-workers demonstrated the enhanced reactivity of $\mathrm{Cu}$ single crystals for acetylene hydrogenation after doping with single Pd atoms. ${ }^{7}$ The authors proposed Pd enabled facile dissociation of hydrogen (compared with activated dissociation of $\mathrm{H}_{2}$ on $\mathrm{Cu}$ ). The atomic $\mathrm{H}$ bound to Pd subsequently spilled over to $\mathrm{Cu}$, catalyzing the hydrogenation of acetylene. Single atom catalysts (SACs) are a related class of catalysts in which individual metal atoms are isolated on refractory or reducible oxides. ${ }^{9-11}$ A major limitation of both SAAs and SACs is their inherent limitation to mononuclear assemblies (i.e., single atoms) because site isolation is accomplished through low surface densities. 
Therefore, SAAs and SACs do not offer the ability to create well-defined homomultinuclear $\left(\mathrm{M}_{n}\right.$, $n>1)$ or heteromultinuclear $\left(\mathrm{M}_{n} \mathrm{M}^{\prime}, n>1\right)$ assemblies.

Goodman and co-workers controlled the coverage of Pd atoms on Au single crystals to demonstrate precise spacing of monomer 'pairs' that facilitated synthesis of vinyl acetate monomer (VAM). ${ }^{6}$ They deposited a low-coverage of Pd atoms on $\mathrm{Au}(111)$ and $\mathrm{Au}(100)$ single crystals, which have different surface interatomic Au spacing, to control spacing between the deposited Pd atoms. The spacing of $\mathrm{Pd}$ atoms on $\mathrm{Au}(100)$ was sufficient to allow the Pd atoms to act as a monomer 'pair' capable of synthesizing VAM, while Pd atoms on $\mathrm{Au}(111)$ were too distant to catalyze VAM formation. This study controlled nuclearity and spacing of active metal atoms (Pd) within a relatively inert host $(\mathrm{Au})$ to provide active and selective catalytic sites. These sites, however, were prepared through a statistical distribution of low coverage Pd atoms rather than targeted synthesis of a specific active metal atom arrangement.

We demonstrate the intermetallic $\gamma$-brass phase of Pd-Zn can be used to directly synthesize both well-defined homomultinuclear and heteromultinuclear active sites. Intermetallic compounds contain at least two metals with a well-defined crystal structure with fixed atom positions and site occupancies, leading to long range order; this offers distinct advantages over SACs and SAAs for controlling active site ensembles beyond single, isolated atoms. The well-defined crystal structure and long-range atomic ordering of intermetallic compounds offer consistent site isolation throughout the catalyst, as well as control over the number of atoms per active site. Beyond this exquisite control over site nuclearity $(n>1)$, homo- and hetero- multinuclear sites can also be prepared with high density on the surface; no comparable synthetic methods exist for SAAs or SACs. 
Intermetallics demonstrate distinct catalytic properties from their corresponding monometallic catalyst. Pd-Ga intermetallics have high acetylene semi-hydrogenation selectivity compared to monometallic Pd. ${ }^{12,13} \mathrm{Li}$ et al. studied $\mathrm{MgO}$ supported Ni-Ga intermetallics and found their selectivity towards phenylacetylene semi-hydrogenation was much higher than pure $\mathrm{Ni}^{14}$ Intermetallic $\beta$-Pd-Zn catalysts expose a checkerboard arrangement of alternating $\mathrm{Pd}$ and $\mathrm{Zn}$ atoms, with distinct selectivity toward acetylene semi-hydrogenation. ${ }^{15}$ These examples demonstrate intermetallics offer more precise control over active site local composition than vapor-deposited bimetallic systems. In the referenced studies, however, control over the geometry and composition of the active site ensembles was limited to isolated single Pd or Ni atoms. Previous work has demonstrated active assemblies of $n$ atoms $\left(n=3\right.$, trimers) in $\operatorname{Pd}_{3} \operatorname{In}(111),{ }^{16} \operatorname{Pt}_{3} \operatorname{Sn}(111)$ and $\mathrm{Pt}_{2} \mathrm{Sn}(111),{ }^{17}$ but these "trimer" active sites are interconnected rather than being isolated by In or Sn atoms. A combined surface science-computational examination of $\operatorname{PdGa}(\overline{1} \overline{1} \overline{1})$ demonstrated the presence of isolated Pd trimers, but their reactivity and selectivity during semi-hydrogenation were not reported. ${ }^{18}$ To date, there has been no demonstration of the ability to synthesize isolated active site ensembles composed of more than one catalytic active metal.

Here, we utilize the intermetallic [Pd, Zn] $\gamma$-brass phase to control the geometry of isolated, active catalytic ensembles dispersed within an inert matrix, as well as the composition of isolated multi-nuclear active sites. The $\gamma$-brass structure is a 52 atom unit cell with four symmetry inequivalent positions - outer tetrahedral (OT), inner tetrahedral (IT), octahedral (OH) and cuboctahedral (CO) (Figure S1). ${ }^{19}$ This precise and homogeneous metal ensemble distribution is maintained at the surface, exposing isolated OT-OH-OT catalytic ensembles. The occupation of the OT-OH-OT ensemble is determined by the composition of the $\gamma$-brass phase. The [Pd, $\mathrm{Zn}]$ binary $\gamma$-brass phase exposes single-atom $\mathrm{Pd}_{1}$ monomers where $\mathrm{Pd}$ atoms are separated by zinc 
(Pd-Zn-Pd) and elongated $\mathrm{Pd}_{3}$ trimer (Pd-Pd-Pd) ensembles (see insets in Figure 1a, b) through simple and subtle stoichiometric tuning (15.4-19.2 at \% Pd). Similarly the $[\mathrm{Pd},(\mathrm{M}), \mathrm{Zn}]_{\mathrm{M}=\mathrm{Au}, \mathrm{Ag}, \mathrm{Cu}}$ $\gamma$-brass phase exposes Pd-M-Pd ensembles through introduction of a heterometal atom during solid-state synthesis.

The compositional control of the catalytic active site within the $\gamma$-brass Pd-Zn phase tunes ethylene hydrogenation activity across orders of magnitude, which has important consequences for selectivity during acetylene semi-hydrogenation. Consistent with the observed activity for ethylene hydrogenation, $\mathrm{Pd}_{1}$ monomers display high selectivity to ethylene, while $\mathrm{Pd}_{3}$ trimers over-hydrogenate ethylene to ethane. The extent of over-hydrogenation can be controlled by breaking up $\mathrm{Pd}_{3}$ trimers through the introduction of a third metal $(\mathrm{M}=\mathrm{Cu}, \mathrm{Ag}, \mathrm{Au})$ during synthesis to create Pd-M-Pd trimers with ethylene selectivity intermediate to $\mathrm{Pd}_{1}$ monomers and $\mathrm{Pd}_{3}$ trimers. The isolated active site with precise compositional control renders these intermetallic catalysts amenable to direct comparison with computational predictions. Density functional theory (DFT) calculations predict the experimental hydrogenation activity and selectivity as the Pd-M-Pd site composition is varied.

\section{Results and Discussion}

\section{Ethylene Hydrogenation Activities on Pd-Zn Binary $\gamma$-brass Intermetallics}

Unsupported Pd-Zn $\gamma$-brass catalysts were synthesized using a well-established bulk synthesis technique and characterized by inductively-coupled plasma - optical emission spectroscopy (ICP-OES), scanning electron microscopy - energy dispersive X-ray spectroscopy (SEM-EDS) and X-ray diffraction (XRD) to ensure phase purity and bimetallic composition. BET surface area was determined to calculate and compare normalized reaction rates. Small changes in 
Pd-Zn ratio result in enormous differences in ethylene hydrogenation activity, which we establish below is due to transition from inactive $\mathrm{Pd}_{1}$ monomers to active $\mathrm{Pd}_{3}$ trimers. As shown in Figure 1a, a Pd-Zn catalyst with $17.3 \mathrm{Pd}$ atomic \% (25.4 wt\%) shows a measurable ethylene hydrogenation activity. This activity doubles upon increasing to $19.2 \mathrm{Pd}$ atomic \% (27.9 $\mathrm{Pd} w \mathrm{w} \%$ ); both $17.3 \%$ and $19.2 \%$ samples have the same activation barrier (Figure 1b). However, a Pd-Zn $\gamma$-brass catalyst with $15.4 \mathrm{Pd}$ atomic $\%(22.8 \mathrm{Pd} \mathrm{wt} \%)$ shows no measurable activity for ethylene hydrogenation. Based on a conservative flame ionization detection limit, the hydrogenation rate over the $15.4 \mathrm{Pd}$ atomic $\%$ catalyst was less than $10^{-13} \mathrm{~mol} \mathrm{~m}^{-2} \mathrm{~s}^{-1}$, at least four orders of magnitude lower than the rate measured over the $17.3 \mathrm{Pd}$ atomic \% catalyst at $307 \mathrm{~K}$.

DFT calculations indicate $\mathrm{Pd}_{1}$ sites are inactive for ethylene hydrogenation whereas $\mathrm{Pd}_{3}$ sites demonstrate measurable activity. Figure 1c reports DFT calculations of the ethylene hydrogenation barrier and desorption energies on the $\gamma$-brass (1 $1 \overline{1} 0) \mathrm{Pd}_{8} \mathrm{Zn}_{44}\left(\mathrm{Pd}_{1}\right.$ monomers, 15.4 $\mathrm{Pd}$ atomic\%), $\mathrm{Pd}_{9} \mathrm{Zn}_{43}\left(\mathrm{Pd}_{1}\right.$ monomers and $\mathrm{Pd}_{3}$ trimers, $17.3 \mathrm{Pd}$ atomic\%), $\mathrm{Pd}_{10} \mathrm{Zn}_{44}$ (doubling of $\mathrm{Pd}_{3}$ trimer density, 19.2 Pd atomic\%), and extended Pd(111) surfaces. We will refer to these three $\gamma$-brass phase compositions as 8-Pd, 9-Pd, and 10-Pd, leaving off the remaining $\mathrm{Zn}$ stoichiometry that completes the 52 atom unit cell. The $\mathrm{Pd}_{1}$ monomer site, exposed on the surface of all three $\gamma$ brass compositions, does not provide a sufficient Pd ensemble to bind ethylene, activate $\mathrm{H}_{2}$, and form the ethylene hydrogenation transition state. This leads to a hydrogenation barrier significantly exceeding the ethylene desorption energy, a reliable descriptor for ethylene hydrogenation activity. ${ }^{20}$ In contrast the $\mathrm{Pd}_{3}$ trimers in 9-Pd and 10-Pd provide a sufficient active site ensemble and, therefore, the hydrogenation barrier is similar to the desorption energy and the catalyst is active for ethylene hydrogenation. 
The lack of ethylene hydrogenation activity on the 8-Pd catalyst is due to the complete isolation of all $\mathrm{Pd}$ atoms as $\mathrm{Pd}_{1}$ monomers, surrounded by all $\mathrm{Zn}$ nearest neighbors. This catalyst exposes "single atom" $\mathrm{Pd}$ sites despite a relatively high $15.2 \mathrm{Pd}$ atomic $\%$ due to the intermetallic nature of the $\gamma$-brass Pd-Zn structure. The $\pi$-bound ethylene on $\mathrm{Pd}_{1}$ monomers blocks $\mathrm{H}$ coadsorption and formation of the hydrogenation transition state. The drastic increase in ethylene hydrogenation activity at 9-Pd occurs due to the formation of $\mathrm{Pd}_{3}$ trimers, also isolated from other surface Pd atoms by Zn nearest neighbors. Further increasing the Pd content to 10-Pd doubles the ethylene hydrogenation rate without changing the apparent activation barrier (Figure 1b), suggesting the doubling of $\mathrm{Pd}_{3}$ ensembles doubles the surface density of active sites. Hydrogenation rates over Pd-Zn catalysts are four orders of magnitude lower than Pd foil, indicating a distinct active site of the Pd-Zn catalysts. We confirm below through XRD and computational modeling that the varying site occupations in the Pd-Zn ratio $\gamma$-brass intermetallic structure generate isolated $\mathrm{Pd}_{1}$ monomers in 8-Pd, $\mathrm{Pd}_{3}$ trimers in 9-Pd, and a doubling of the $\mathrm{Pd}_{3}$ trimer surface density in 10-Pd, showing unprecedented control of the nuclearity of Pd active sites. 

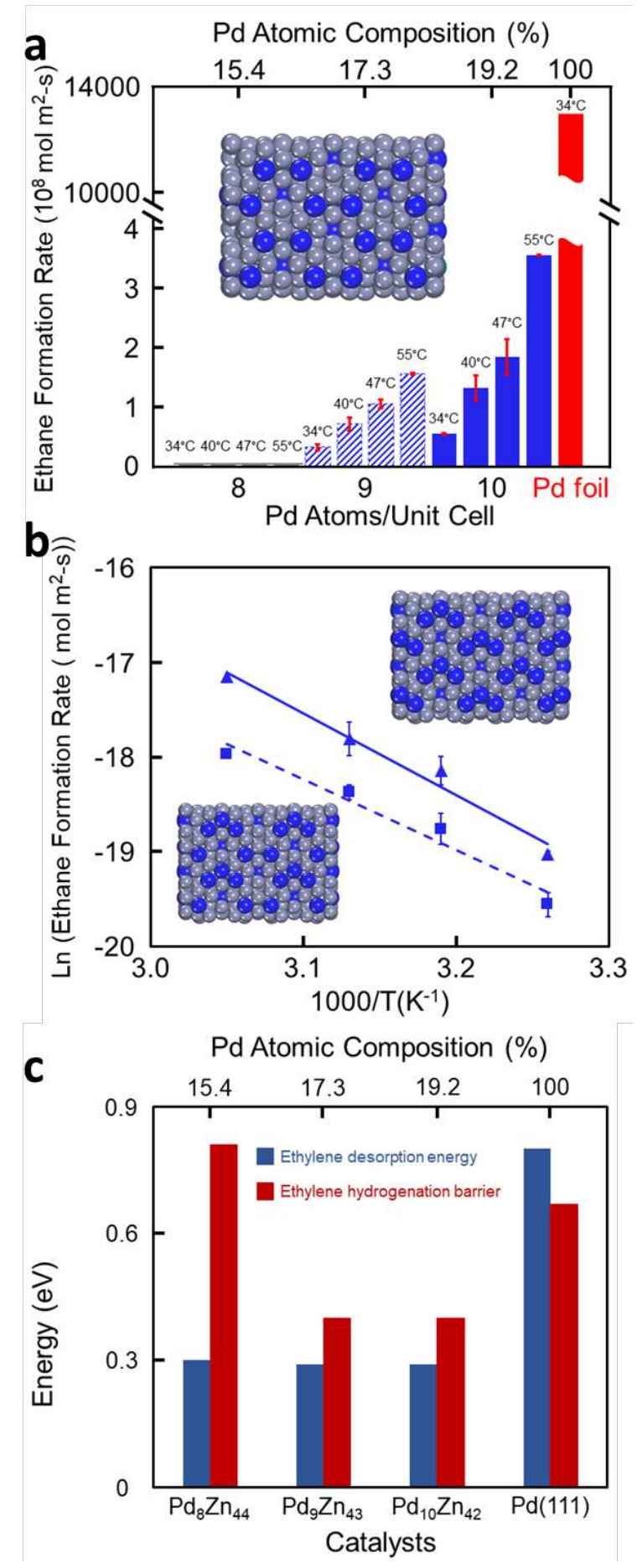

Figure 1. Hydrogenation of ethylene over $\gamma$-brass [Pd, Zn] catalysts. (a) Ethylene hydrogenation activity at different temperatures $\left(34^{\circ} \mathrm{C}, 40^{\circ} \mathrm{C}, 47^{\circ} \mathrm{C}, 55^{\circ} \mathrm{C}\right)$ on $\mathrm{Pd}_{8} \mathrm{Zn}_{44}, \mathrm{Pd}_{9} \mathrm{Zn}_{43}$, $\mathrm{Pd}_{10} \mathrm{Zn}_{42}$ and $\mathrm{Pd}$ foil with $\mathrm{C}_{2} \mathrm{H}_{4}: \mathrm{H}_{2}=1: 40$. (inset) Corresponding DFT calculated most stable 
surface of $\mathrm{Pd}_{8} \mathrm{Zn}_{44}$, (b) Arrhenius plot for ethylene hydrogenation over $\mathrm{Pd}_{9} \mathrm{Zn}_{43}$ (square) and $\mathrm{Pd}_{10} \mathrm{Zn}_{42}$ (triangle) in the temperature range $34-55^{\circ} \mathrm{C}$ with 5 Torr ethylene, 200 Torr hydrogen and balance He. (inset, left) DFT calculated most stable surface facet of $\mathrm{Pd}_{9} \mathrm{Zn}_{43}$ exposing $\mathrm{Pd}_{3}$ trimer ensemble. (inset, right) DFT calculated most stable surface facet of $\mathrm{Pd}_{10} \mathrm{Zn}_{42}$ exposing double $\mathrm{Pd}_{3}$ trimer ensemble. (c) DFT calculated ethylene hydrogenation barrier and desorption energy on $\operatorname{Pd}_{8} Z_{44}(1 \overline{1} 0), \operatorname{Pd}_{9} Z_{43}(1 \overline{1} 0), \operatorname{Pd}_{10} Z_{42}(1 \overline{1} 0)$ and $\operatorname{Pd}(111)$ surfaces. 


\section{Synthesis and Characterization of $[\mathrm{Pd}, \mathrm{Zn}]$ and $[\mathrm{Pd}, \mathrm{M}, \mathrm{Zn}] \gamma$-brass Intermetallics}

The $[\mathrm{Pd}, \mathrm{Zn}]$ intermetallic compound allows us to systematically vary Pd content and thus the ensemble size of the active site. At the lower solubility limit of 8-Pd $\left(\operatorname{Pd}_{8} Z_{44}\right)$, Rietveld refinement of XRD data revealed all $8 \mathrm{Pd}$ atoms occupy the OT site. This has important consequences for the surface structure of the catalyst, as the Pd atoms are isolated from one another by $\mathrm{Zn}$ (Section S3 and Table S2). ${ }^{21}$ Increasing the Pd fraction beyond $\mathrm{Pd}_{8} \mathrm{Zn}_{44}$ leads to $\mathrm{Pd}$ occupation of the $\mathrm{OH}$ site (Table S2 and Figures S3 and S4); forming either $1 \mathrm{Pd}_{3}(9-\mathrm{Pd})$ or $2 \mathrm{Pd}_{3}$ (10-Pd) trimers per unit cell, which are exposed on the (11̄0) facet (Figure 2a) of the material.

A first-principles based cluster expansion method (CEM) ${ }^{22}$ was employed to confirm the lowest-energy configuration among all the independent configurations (the total number of configurations is $2^{26}$ or $6.7 \times 10^{7}$ ) of 8 -Pd and 10 -Pd $\gamma$-brass phase using a 26 -atom sublattice model of $(\mathrm{Pd}, \mathrm{Zn})_{4}^{\mathrm{OT}}(\mathrm{Pd}, \mathrm{Zn})_{4}^{\mathrm{IT}}(\mathrm{Pd}, \mathrm{Zn})_{6}^{\mathrm{OH}}(\mathrm{Pd}, \mathrm{Zn})_{12}^{\mathrm{CO}}{ }^{20}$ (Figure $2 \mathrm{~b}$, for more details see Section $\left.\mathrm{S} 10\right)$. The CEM demonstrated the lowest energy configuration for 8-Pd places all 8 Pd in OT sites, whereas for 10-Pd, 8 Pd occupy OT sites and $2 \mathrm{Pd}$ occupy OH sites. These results agree with our DFT calculations (Figures S3 and S4) and XRD Rietveld refinement results. In contrast to our previous research on the Ni-Zn $\gamma$-brass phase, ${ }^{23}$ DFT calculations for the Pd-Zn $\gamma$-brass phase indicate a trimer containing (110) surface termination is energetically stable (Tables S4 and S5) and substantially ( $\sim 50 \%$ area basis) exposed in the Wulff particle construction (Figure $2 \mathrm{c}$ ) for PdZn $\gamma$-brass materials.

DFT was also used to consider the possibility of surface reconfiguration in which Pd surface aggregation ( $\mathrm{Pd}$ monomers exchanged with $\mathrm{Zn}$ to expand the $\mathrm{Pd}$ trimer ensemble), and subsurface-to-surface exchange (sub-surface $\mathrm{Pd}$ atoms exchanged with $\mathrm{Zn}$ to expand the $\mathrm{Pd}$ trimer 
ensemble) were considered. All reconfigurations were found to have highly unfavorable formation energies because these restructuring events require $\mathrm{Pd}$ atoms to reside in $\mathrm{Zn}$-occupied surface lattice positions - an inherently unstable local atomic composition (Figure 2d). Thus, the combined experimental, CEM and DFT calculations demonstrated the Pd-Zn intermetallics with composition ranging from 8-Pd to 10-Pd could be synthesized with high phase purity and well-defined lattice siting. DFT calculations further confirmed $\mathrm{Pd}_{3}$ trimers were stable and present on $(1 \overline{1} 0)$, a predominant exposed facet. 

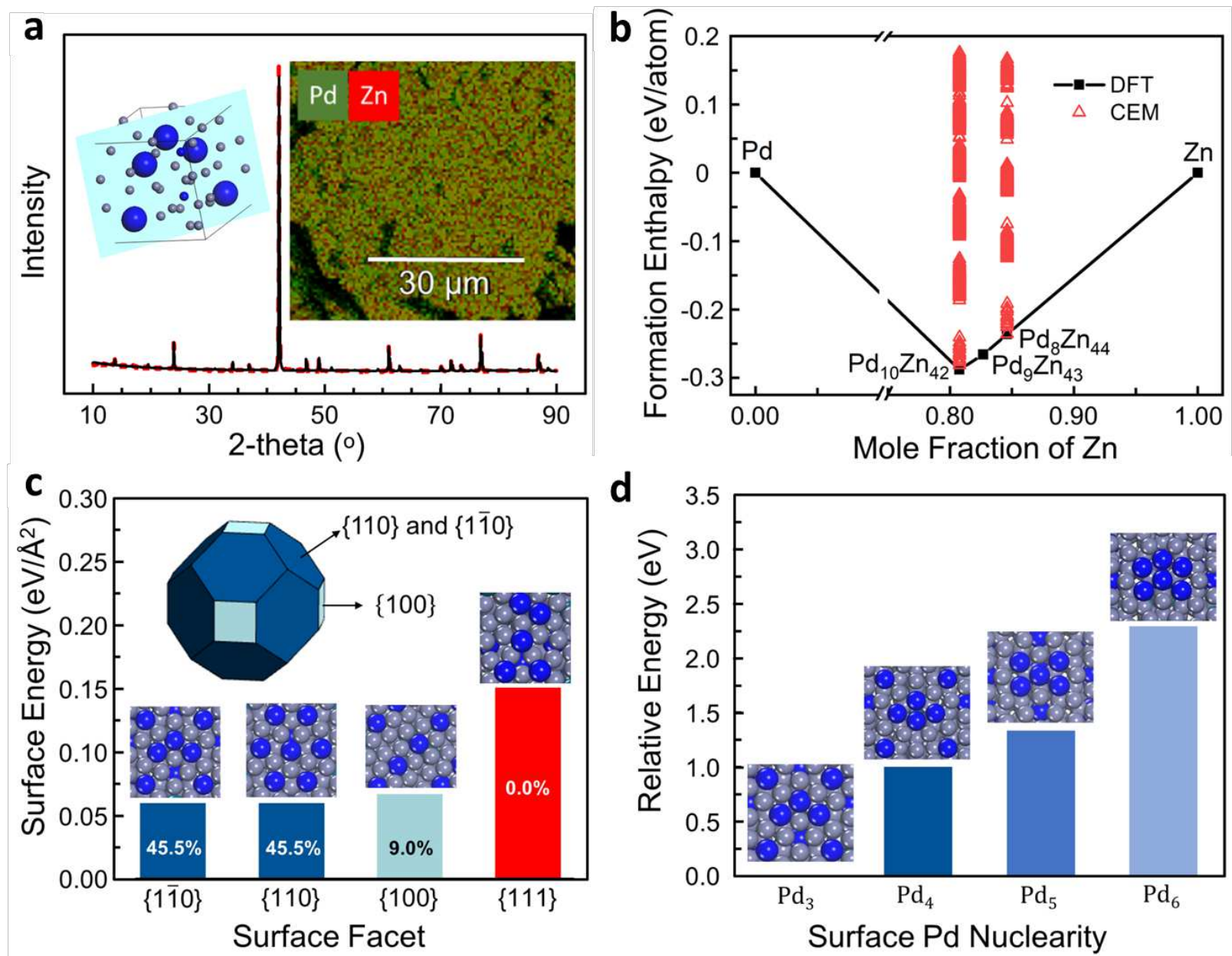

Figure 2. X-Ray Diffraction and Density Functional Theory results show the location of Pd atoms in the bulk and surface of $[\mathbf{P d}, \mathbf{Z n}] \boldsymbol{\gamma}$-brass structures. (a) XRD (black line) with Rietveld refinement fit (red dash) for $\mathrm{Pd}_{9} \mathrm{Zn}_{43}$. (inset, left) Rietveld refinement derived $\gamma$-brass crystal structure showing trimer Pd-M-Pd (in this case $\mathrm{M}=\mathrm{Pd}$ ) sites along the $\{1 \overline{1} 0\}$ orientation in the crystal lattice. (inset, right) Corresponding SEM-EDS showing homogenous distribution of $\mathrm{Pd}$ and $\mathrm{Zn}$. (b) The formation enthalpies of $\mathrm{Pd}-\mathrm{Zn} \gamma$-brass configurations at $0 \mathrm{~K}$ are referenced to FCC Pd and HCP Zn. The black line is the convex hull determined by DFT calculations, the red triangles are the CEM results for $\mathrm{Pd}_{8} \mathrm{Zn}_{44}$ and $\mathrm{Pd}_{10} \mathrm{Zn}_{42}$ configurations. (c) DFT surface energies of low index facets for $\mathrm{Pd}_{9} \mathrm{Zn}_{43}$ along with the most favored termination for each orientation and 
the corresponding Wulff construction. Numbers in the bar diagram represent relative exposure of respective terminations in the Wulff construction. The $\{110\}$ facet has two equally stable terminations (depicted here as $(1 \overline{1} 0)$ and $(110)$ by virtue of the 4-fold crystal symmetry of the $\gamma$ brass phase) one having $\mathrm{Pd}_{3}$ sites and the other only $\mathrm{Pd}_{1}$ sites. From a Wulff construction of a particle, $\sim 45.5 \%$ of the exposed surface area contains trimer sites (in addition to monomer sites which decrease in number per unit cell with Pd addition) (Tables S4 and S5). (d) Relative energies of restructured $\mathrm{Pd}_{9} \mathrm{Zn}_{43}(1 \overline{1} 0)$ surfaces relative to the bulk-terminated, $\mathrm{Pd}_{3}$ trimer containing surface. $\mathrm{Pd}_{4}$ is constructed by swapping a sub-surface $\mathrm{Pd}$ with a $\mathrm{Zn}$ in the surface. $\mathrm{Pd}_{5}$ is constructed by swapping $2 \mathrm{Pd}$ monomers on the surface with $\mathrm{Zn}$ atoms adjacent to the $\mathrm{Pd}_{3}$ trimer. $\mathrm{Pd}_{6}$ is constructed by swapping Pd from the sub-surface and $2 \mathrm{Pd}$ monomers on the surface with $\mathrm{Zn}$ atoms adjacent to the $\mathrm{Pd}_{3}$ trimer. 


\section{Influence of Active Site Nuclearity (Pd-M-Pd trimer) on Catalytic Semi-Hydrogenation}

Acetylene hydrogenation serves as a probe reaction to demonstrate how the relative density of isolated Pd sites impacts both hydrogenation activity and selectivity. Our experimental studies indicate $\mathrm{Pd}_{1}$ monomers hydrogenate $\mathrm{C}-\mathrm{C}$ triple bonds at a rate two orders of magnitude slower than $\mathrm{Pd}_{3}$ trimers. Computational studies demonstrate the central atom of the Pd-M-Pd active ensemble plays a controlling role in governing catalyst performance. DFT calculations predict that, just as for $\mathrm{Pd}_{9} \mathrm{Zn}_{43}$, replacement of a single $\mathrm{Zn}$ atom in $\mathrm{Pd}_{8} \mathrm{Zn}_{44}$ by a coinage metal atom results in the formation of stable Pd-M-Pd ensembles $(\mathrm{M}=\mathrm{Cu}, \mathrm{Ag}, \mathrm{Au})$ both in the bulk and, more importantly, at the surface. Further, the catalytic performance (acetylene-ethylene competitive hydrogenation) of $\mathrm{Pd}-\mathrm{M}-\mathrm{Pd}$ ensembles is between $\mathrm{Pd}_{1}$ and $\mathrm{Pd}_{3}$.

Experiments confirm these predictions. As shown in Figure 3(a), acetylene hydrogenation activity increased by over two orders of magnitude from 8-Pd to 9-Pd, indicating a distinct change in active site morphology, which we attribute to the transition from $\mathrm{Pd}_{1}$ to $\mathrm{Pd}_{3}$ active sites. From 9-Pd to 10-Pd the areal rate doubles, due to the doubling of $\mathrm{Pd}_{3}$ sites (as for ethylene hydrogenation) that overshadows any kinetic impact of the corresponding decrease in the number of $\mathrm{Pd}_{1}$ sites. $\mathrm{Pd}$ foil exhibits an order of magnitude higher rate per area than 10-Pd and significantly lower ethylene selectivity. 8-Pd, consisting of only $\mathrm{Pd}_{1}$ monomers on the surface, demonstrates high selectivity towards ethylene, due to its inactivity to hydrogenate ethylene, as previously discussed.

DFT calculations provide elementary reaction energetics that agree with the experimentally observed impact of $\mathrm{Pd}_{\mathrm{n}}$ nuclearity on acetylene hydrogenation activity. On the 8-Pd surface, acetylene adsorbs in a di- $\sigma$ mode across $\mathrm{Pd}_{1}-\mathrm{Pd}_{1}$ monomer sites $\left(\mathrm{Pd}_{1}\right.$ sites are spaced by $\left.4.42 \AA\right)$, whereas on the 9-Pd surface, acetylene adsorbs at $\mathrm{Pd}_{3}$ hollow sites. Such adsorption configurations are consistent with literature. ${ }^{13,14,18}$ DFT energetics (Figure 3b, for more details see Figure S10 
and Table S6) indicate both $\mathrm{Pd}_{1}$ and $\mathrm{Pd}_{3}$ sites have surmountable barriers for acetylene hydrogenation to ethylene. The di- $\sigma$ binding mode of acetylene leaves room for $\mathrm{H}$ co-adsorption and hydrogenation transition state formation on $\mathrm{Pd}_{1}$ sites. $\mathrm{Pd}_{3}$ sites, however, have significantly lower $\mathrm{C}-\mathrm{H}$ bond formation barriers than $\mathrm{Pd}_{1}$ sites. Acetylene and hydrogen adsorption energies on the $\mathrm{Pd}(111)$ surface are significantly stronger than 8-Pd and 9-Pd, as shown in Figure 3b, indicating higher surface coverage of acetylene and hydrogen, and thus higher hydrogenation rate. DFT predictions agree with experimental observations that 8-Pd, 9-Pd, 10-Pd, and extended $\mathrm{Pd}$ surfaces are active for acetylene hydrogenation, with increasing activity as the Pd content increases.

DFT calculated elementary reaction energetics also predict the observed acetylene semihydrogenation selectivity for $8-\mathrm{Pd}$, exposing $\mathrm{Pd}_{1}$ active sites. The $\mathrm{DFT}$ calculated ethylene hydrogenation barrier is significantly higher than the desorption energy on $\mathrm{Pd}_{1}$ sites, indicating high selectivity towards ethylene formation. However, on the $\mathrm{Pd}_{3}$ sites, the ethylene hydrogenation barrier is similar to the desorption energy, and hydrogenation becomes kinetically preferred on $\operatorname{Pd}(111)$. The difference between ethylene hydrogenation barrier and desorption energy on $\operatorname{Pd}_{1}$ sites, $\mathrm{Pd}_{3}$ sites and $\mathrm{Pd}(111)$ is in agreement with the experimental observation of decreasing ethylene selectivity with increasing Pd content.

The central atom of the Pd-M-Pd active ensemble plays a controlling role in governing ethylene hydrogenation activity because it controls the apparent barrier for $\mathrm{C}-\mathrm{H}$ bond formation. With the middle atom of the trimer active ensemble replaced with a coinage metal (both in the bulk and more importantly on the surface) to form $\mathrm{Pd}-\mathrm{M}-\mathrm{Pd}$ ensembles $(\mathrm{M}=\mathrm{Cu}, \mathrm{Ag}, \mathrm{Au})$, activation barriers intermediate to $\mathrm{Pd}_{1}$ and $\mathrm{Pd}_{3}$ are calculated for both ethylene and acetylene hydrogenation, as shown in Figure 3c. The difference between ethylene hydrogenation and desorption barriers can be tuned between $0.51 \mathrm{eV}$ on Pd-Zn-Pd to $0.11 \mathrm{eV}$ on Pd-Pd-Pd, with the Pd-M-Pd series giving 
intermediate values ( $0.32 \mathrm{eV}$ on Pd-Au-Pd, $0.28 \mathrm{eV}$ on Pd-Ag-Pd and $0.24 \mathrm{eV}$ on Pd-Cu-Pd, Figure 3d). The acetylene hydrogenation barrier is similarly tunable as shown in Figure 3c. DFT results, therefore, predict addition of coinage metals in Pd-M-Pd sites will lead to acetylene hydrogenation activity and selectivity values intermediate to $8-\mathrm{Pd}$ and $9-\mathrm{Pd}$. DFT calculation of reaction energies clearly demonstrate the nuclearity of the Pd-M-Pd active site can finely tune activity and selectivity. We demonstrate these predictions can be confirmed experimentally utilizing a synthetic approach with precise control of active site composition. 

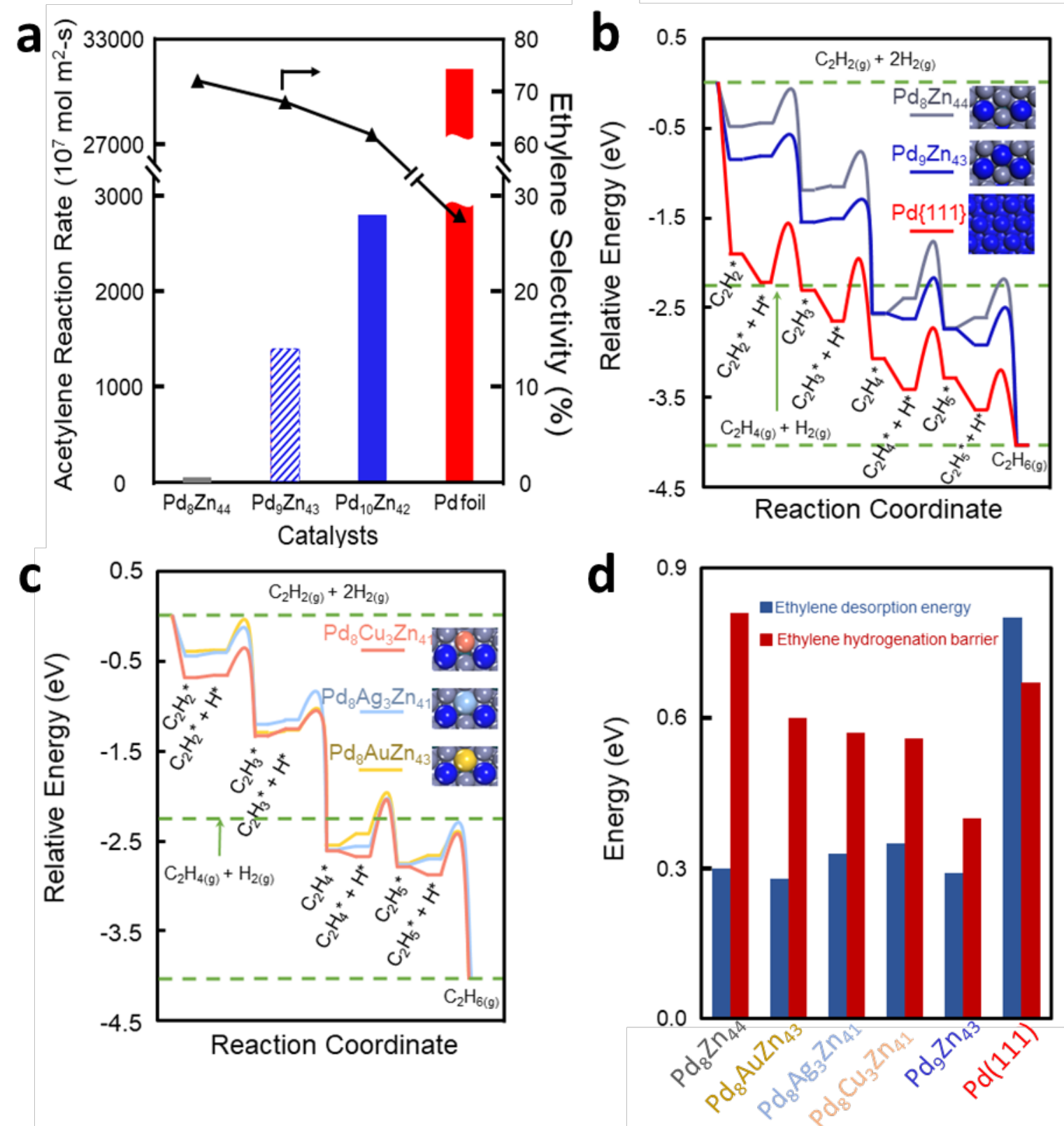

Figure 3: Experimental study of acetylene hydrogenation on Pd-Zn intermetallics and Pd foil and DFT reaction energy diagrams for acetylene hydrogenation on $\mathrm{Pd}-\mathrm{M}-\mathrm{Pd}(\mathrm{M}=\mathrm{Zn}$, Pd, Au, Ag, Cu) sites. (a) Acetylene hydrogenation results at $160^{\circ} \mathrm{C}$ using $\mathrm{C}_{2} \mathrm{H}_{2}: \mathrm{H}_{2}=1: 100$. (b)(c) Acetylene hydrogenation energy diagram on Pd-M-Pd. (d) Ethylene desorption energy and hydrogenation barrier on Pd-M-Pd. Structures with further details are presented in Table S6 and Figure S10. 
Solid state diffusion, in a flame-sealed and evacuated quartz ampoule, at $800{ }^{\circ} \mathrm{C}$ was used to prepare ternary $\gamma$-brass intermetallics. XRD confirms phase pure $[\mathrm{Pd}, \mathrm{M}, \mathrm{Zn}](\mathrm{M}=\mathrm{Cu}, \mathrm{Ag}, \mathrm{Au})$ $\gamma$-brass materials can be synthesized (Figure S2). Using similar Rietveld refinement and DFT calculations, as described earlier (Section S3-6, Tables S3-S5 and Figure S5-S9) for [Pd, Zn], it is further confirmed Pd-M-Pd active sites form in $[\mathrm{Pd}, \mathrm{M}, \mathrm{Zn}] \gamma$-brass materials because $(i) \mathrm{M}$ preferentially replaces $\mathrm{Zn}$ from $\mathrm{OH}$ sites and (ii) exposure of Pd-M-Pd trimers at the surface is energetically favorable in all these materials.

We used ${ }^{13} \mathrm{C}_{2}$-ethylene and ${ }^{12} \mathrm{C}_{2}$-acetylene to independently track conversion and allow for rigorous quantification of semi-hydrogenation selectivity during the hydrogenation of acetylene in excess ethylene (Section S9). $\mathrm{Pd}_{8} \mathrm{Zn}_{44}, \mathrm{Pd}_{9} \mathrm{Zn}_{43}$ and $\mathrm{Pd}_{8} \mathrm{AuZn}_{43}$ had comparable intrinsic ethylene selectivity $\left(=\frac{{ }^{12} C_{2} H_{4}}{\Delta^{12} C_{2} H_{2}}\right.$, Figure $\left.4 a\right)$ similar to ethylene selectivity for non-competitive acetylene hydrogenation (Figure 3a). More importantly, the net semi-hydrogenation selectivity $(=$ $\frac{{ }^{12} C_{2} H_{4}-{ }^{13} C_{2} H_{6}}{\Delta^{12} C_{2} H_{2}}$, Figure 4a) on $\mathrm{Pd}_{3}$ trimers on $\mathrm{Pd}_{9} \mathrm{Zn}_{43}$ is far below its intrinsic value because of the simultaneous hydrogenation of ${ }^{13} \mathrm{C}_{2}$-ethylene. Net ethylene selectivity for $\mathrm{Pd}_{8} \mathrm{Zn}_{44}$ is within $\sim 15 \%$ of its intrinsic value (and far superior to $\mathrm{Pd}_{9} \mathrm{Zn}_{43}$ ) even at $\sim 100 \%$ acetylene conversion (Figure $4 \mathrm{~b}$ ). The single $\mathrm{Pd}$ atoms cannot supply hydrogen to $\mathrm{C}$-C double bonds because $\pi$-bound ethylene blocks $\mathrm{H}_{2}$ dissociative adsorption, $\mathrm{H}$ co-adsorption and $\mathrm{C}=\mathrm{C}$ hydrogenation, whereas di- $\sigma$ acetylene binding across a $\mathrm{Pd}$ monomer "pair" allows $\mathrm{H}$ co-adsorption and $\mathrm{C} \equiv \mathrm{C}$ hydrogenation. $\mathrm{Pd}_{8} \mathrm{AuZn}_{43}$ demonstrates an intermediate net ethylene selectivity between $\mathrm{Pd}_{8} \mathrm{Zn}_{44}$ and $\mathrm{Pd}_{9} \mathrm{Zn}_{43}$, due to the trimer ensemble modification as predicted by DFT calculations. Figures S11 and S12 demonstrate $\mathrm{Pd}_{8} \mathrm{Ag}_{3} \mathrm{Zn}_{41}$ and $\mathrm{Pd}_{8} \mathrm{Cu}_{3} \mathrm{Zn}_{41}$ have intermediate activities and selectivites between 8Pd and 9-Pd catalysts. 

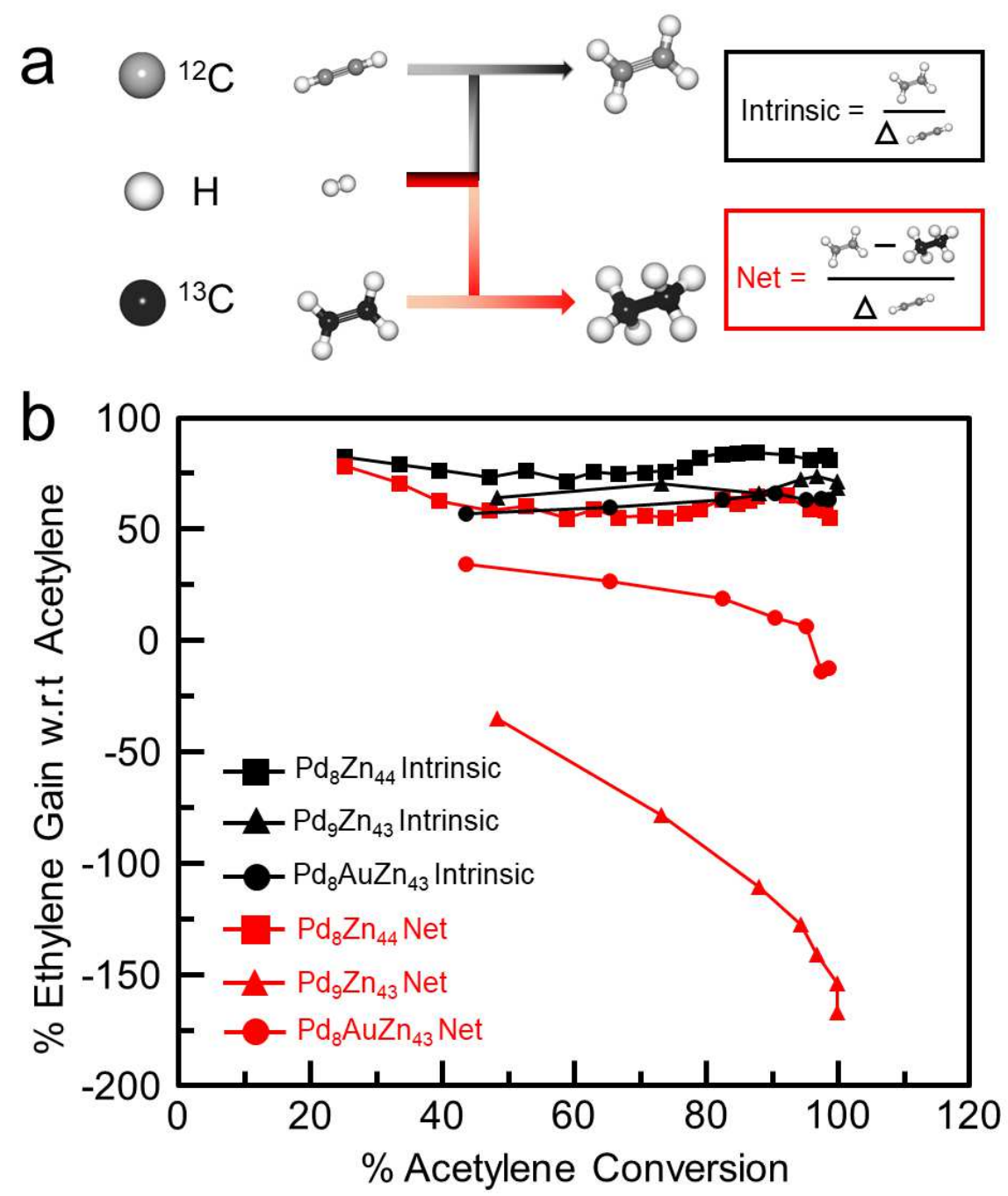

Figure 4. Competitive hydrogenation of ${ }^{13} \mathrm{C}_{2}$-ethylene and ${ }^{12} \mathrm{C}_{2}$-acetylene mixed feed over $\gamma$ brass $[\mathbf{P d},(\mathbf{A u}) \mathbf{Z n}]$ catalysts. (a) ${ }^{13} \mathrm{C}$ (black) $)_{2}$-ethylene and ${ }^{12} \mathrm{C}(\text { grey })_{2}$-acetylene reaction path and definition of intrinsic and net selectivity. Note the net selectivity can take on negative values if the rate of ${ }^{13} \mathrm{C}$-ethylene hydrogenation is greater than the rate of ${ }^{12} \mathrm{C}$-acetylene hydrogenation. (b) Net and intrinsic ethylene hydrogenation selectivity of $\mathrm{Pd}_{8} \mathrm{Zn}_{44}$ (red and black square, respectively), $\mathrm{Pd}_{9} \mathrm{Zn}_{43}$ (red and black triangle, respectively) and $\mathrm{Pd}_{8} \mathrm{AuZn}_{43}$ (red and black circle, respectively) at $160{ }^{\circ} \mathrm{C},{ }^{12} \mathrm{C}_{2} \mathrm{H}_{2}:{ }^{13} \mathrm{C}_{2} \mathrm{H}_{4}: \mathrm{H}_{2}=1: 31: 18$. 
As a final proof of precise control over these model catalytic systems, we correlate DFT performance descriptors $\left(\exp \left(-\frac{E_{C_{2} \mathrm{H}_{2} h y d r o}^{a c t}}{R T}\right)\right.$ for activity and $E_{C_{2} H_{4} \text { hydro }}^{a c t}-E_{C_{2} H_{4} \text { des }}$ for selectivity) with experimental performance (Figure 5). The first acetylene $\mathrm{C}-\mathrm{H}$ formation barrier is a reasonable descriptor for acetylene hydrogenation activity given the strong adsorption of acetylene. The difference of ethylene hydrogenation barrier and desorption energy is used as a selectivity descriptor, as applied previously. ${ }^{20,24}$ Both activity and selectivity show strong agreement between experimental kinetics and DFT, thus providing evidence of excellent control of these multinuclear-heteroatomic active ensembles through subtle stoichiometric tuning and introduction of an additional metal atom. 

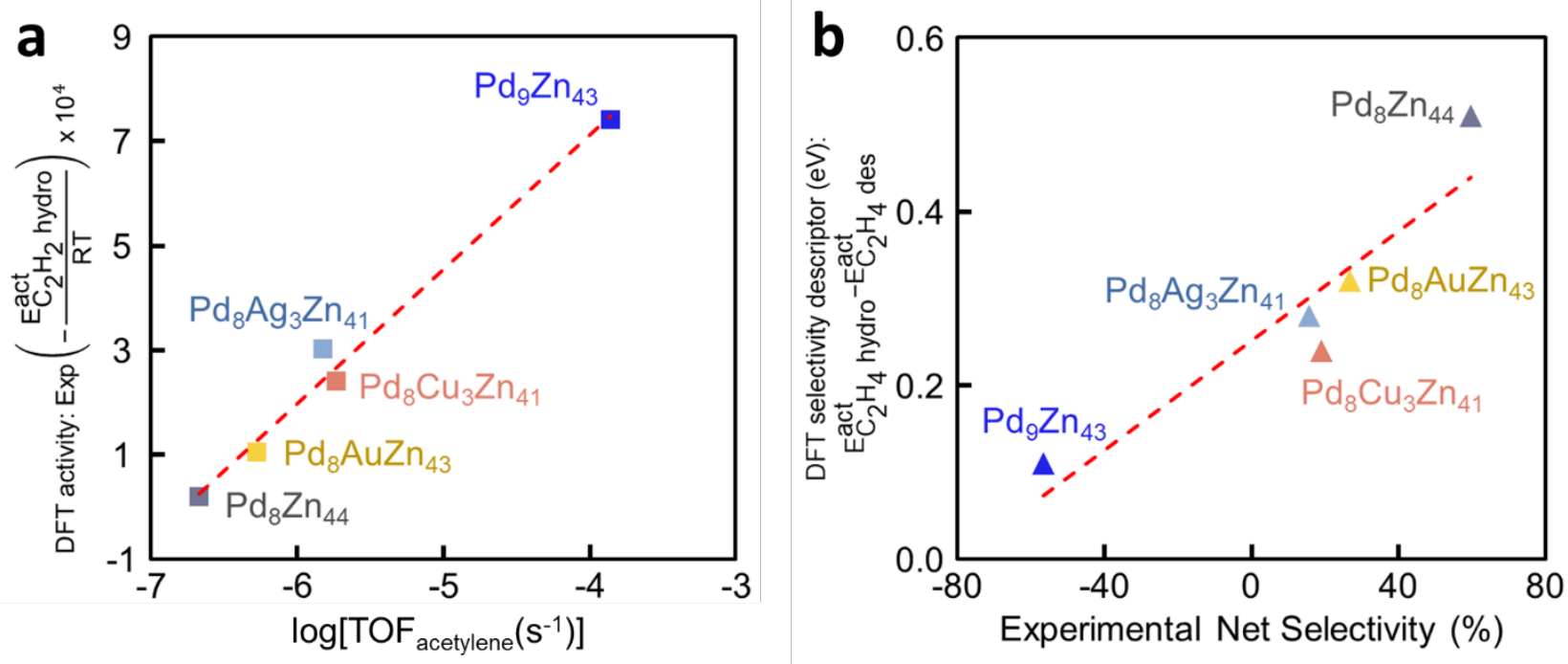

Figure 5. Experimental and computational comparison of acetylene semi-hydrogenation on $\boldsymbol{\gamma}$-brass [Pd, (M), Zn] $(\mathbf{M}=\mathbf{Z n}, \mathbf{P d}, \mathbf{C u}, \mathbf{A g}, \mathbf{A u})$. Qualitative agreement between experimental activity (a) and selectivity (b) with corresponding DFT descriptors to evaluate catalyst performance for acetylene semi-hydrogenation. 
In conclusion, we demonstrate the $[\mathrm{Pd},(\mathrm{M}), \mathrm{Zn}] \gamma$-brass crystal structure can be manipulated to reliably access well-defined, isolated, catalytically relevant 3-atom active sites of the form Pd-M-Pd which are distinct amongst themselves and from fully coordinated Pd sites. These model surfaces demonstrate the impact of active atom nuclearity on catalytic performance in Pd-catalyzed hydrogenation chemistry. These precise Pd-M-Pd ensembles are experimentally easy to access and convenient for DFT modeling due to their single crystal-like nature to enable probing the impact of active site nuclearity on catalytic activity and selectivity. From this work, the use of intermetallic compounds can be extended to create active sites that are potentially tuned to the molecular footprint of any hydrocarbon reactant/product of interest. Such materials will be key in the pursuit of atomically precise active site generation for selective conversion with high atom efficiency.

\section{Methods}

The $\gamma$-brass phase materials were synthesized using a solid-state diffusion method. ${ }^{21,25-27}$ X-ray diffraction (XRD) was performed on a PANalytical X'pert Pro instrument using constant wavelength $\mathrm{Cu} \mathrm{K} \mathrm{K}_{\alpha}$ radiation. A graphite monochromator was used on the detector side to cut off $\mathrm{K}_{\beta}$ peaks that can interfere with refinement. Rietveld refinement was conducted using the EXPGUI interface of the General Structure Analysis System (GSAS) software package. ${ }^{28,29}$ Ethylene hydrogenation experiments were performed in a fritted glass tube (10 mm ID, ChemGlass) operating as a plug-flow reactor. Catalysts were reduced for $8 \mathrm{~h}$ at $250^{\circ} \mathrm{C}$ in hydrogen and then held for $20 \mathrm{~min}$ at that temperature under He flow before being cooled under He flow to the desired reaction temperature. The product stream was analyzed with an online Hewlett Packard 5890 Series II GC. All conversions were below 10\% and may be considered differential. Competitive acetylene and isotopically-labeled ethylene hydrogenation was performed in a home-made batch 
reactor similar to that used by Spanjers et al. ${ }^{26}$ The reactor tube had an outer diameter of $5 \mathrm{~mm}$. The batch reactor was evacuated to $180 \mathrm{mTorr}$ before filling with reactant gases. The catalyst was initially reduced for $4 \mathrm{~h}$ at $250^{\circ} \mathrm{C}$ by evacuating the set-up and back-filling to $\sim 850$ Torr hydrogen. It was then cooled to room temperature, evacuated, and filled with 550 Torr 1\% acetylene, 170 Torr ${ }^{13} \mathrm{C}_{2}$-ethylene (99\%, Sigma Aldrich), 100 Torr hydrogen (UHP, Praxair) and 20 Torr Ar (UHP, Praxair) and subsequently heated up to the reaction temperature. Gases were sampled via a 100 $\mu \mathrm{L}$ gas-tight syringe (Hamilton Company) and the products analyzed with a Shimadzu 2010 QP Ultra GC-MS. The Ar signal $(\mathrm{m} / z=40)$ is used as an internal standard to correct for fluctuations in sample injection volume. Details on the synthesis, characterization, and reactivity studies of the $[\mathrm{Pd},(\mathrm{M}), \mathrm{Zn}] \gamma$-brass intermetallics are available in the Supplementary Information.

All DFT calculations were performed using the Vienna Ab Initio Simulation Package (VASP). ${ }^{30-}$ 32 The Perdew-Burke-Ernzerhoff (PBE) generalized gradient approximation was applied with a plane wave basis set with energy cutoff of $450 \mathrm{eV} .{ }^{33}$ The Methfessel-Paxton (MP) smearing method was applied in all calculations with a broadening value of $0.2 \mathrm{eV} \cdot{ }^{34}$ Structural optimizations were carried out until forces on all atoms were less than $0.05 \mathrm{eV} / \AA$. A $6 \times 6 \times 6$ Monkhorst-Pack k-point mesh sampling was used for bulk $\left(\mathrm{Pd}_{8} Z_{44}, \mathrm{Pd}_{9} \mathrm{Zn}_{43}, \mathrm{Pd}_{10} \mathrm{Zn}_{42}\right.$, $\mathrm{Pd}_{8} \mathrm{AgZn}_{43}, \mathrm{Pd}_{8} \mathrm{CuZn}_{43}$ and $\mathrm{Pd}_{8} \mathrm{AuZn}_{43}$ ) optimization. ${ }^{35}$ The nudged elastic band (NEB) method was applied to locate transition states as the highest energy image with tangential force to the reaction coordinate less than $0.05 \mathrm{eV} / \AA$, and each transition state was verified through the existence of a single imaginary vibrational frequency. ${ }^{36}$ Further details on the DFT calculations and CEM are available in the Supplementary Information.

\section{Data Availability}


The datasets generated during and/or analyzed during the current study are available from the corresponding author on reasonable request.

\section{Code Availability}

All computational codes/algorithms utilized in this study were performed with either commercially available or open-source software.

\section{Acknowledgements}

This work is supported by the U.S. Department of Energy, Office of Science, Office of Basic Energy Sciences, Catalysis Division under Award Number DE-SC0020147. A. D. acknowledges financial support from the US National Science Foundation (NSF grant \# CBET-1748365). H.H. acknowledges training provided by the Computational Materials Education and Training (CoMET) NSF Research Traineeship (Grant No. DGE-1449785). This work used the Extreme Science and Engineering Discovery Environment (XSEDE), which is supported by the National Science Foundation under Grant No. ACI-1548562.

\section{Author Contributions}

These authors contributed equally: Anish Dasgupta, Haoran He.

A. D., E. K. Z., and R. M. R. planned, executed, and analyzed the experimental work. H. H. and M. J. J. performed and analyzed the density functional theory computational work. R. G., S. S., and Z. L. performed and analyzed the cluster expansion method work. R. J. M, M. J. J, and R. M. R. conceived the work and supervised the research. A. D. and H. H. wrote the paper with contributions from all authors.

\section{Competing Interest}

The authors declare no competing financial interests. 


\section{References}

1 Norskov, J. K., Bligaard, T., Rossmeisl, J. \& Christensen, C. H. Towards the computational design of solid catalysts. Nature Chemistry 1, 37-46 (2009).

2 Besenbacher, F. et al. Design of a surface alloy catalyst for steam reforming. Science 279, 1913-1915 (1998).

3 Paffett, M. T., Gebhard, S. C., Windham, R. G. \& Koel, B. E. Chemisorption of Ethylene on Ordered Sn/Pt(111) Surface Alloys. Surface Science 223, 449-464 (1989).

4 Rodriguez, J. A. Interactions in Bimetallic Bonding - Electronic and Chemical Properties of PdZn Surfaces. Journal of Physical Chemistry 98, 5758-5764 (1994).

5 Weilach, C. et al. Geometric Arrangement of Components in Bimetallic $\mathrm{PdZn} / \mathrm{Pd}(111)$ Surfaces Modified by CO Adsorption: A Combined Study by Density Functional Calculations, Polarization-Modulated Infrared Reflection Absorption Spectroscopy, and Temperature-Programmed Desorption. Journal of Physical Chemistry C 116, 18768-18778 (2012).

6 Chen, M. S., Kumar, D., Yi, C. W. \& Goodman, D. W. The promotional effect of gold in catalysis by palladium-gold. Science 310, 291-293 (2005).

7 Kyriakou, G. et al. Isolated Metal Atom Geometries as a Strategy for Selective Heterogeneous Hydrogenations. Science 335, 1209-1212 (2012).

8 Zhang, S. R. et al. Catalysis on singly dispersed bimetallic sites. Nature Communications $6(2015)$.

9 Qiao, B. T. et al. Single-atom catalysis of CO oxidation using Pt-1/FeOx. Nature Chemistry 3, 634-641 (2011).

10 Spezzati, G. et al. Atomically Dispersed Pd-O Species on CeO2(111) as Highly Active Sites for Low-Temperature CO Oxidation. Acs Catalysis 7, 6887-6891 (2017).

11 Wei, H. S. et al. FeOx-supported platinum single-atom and pseudo-single-atom catalysts for chemoselective hydrogenation of functionalized nitroarenes. Nature Communications 5 (2014).

12 Kovnir, K. et al. A new approach to well-defined, stable and site-isolated catalysts. Science and Technology of Advanced Materials 8, 420-427 (2007).

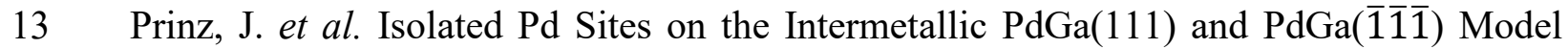
Catalyst Surfaces. Angewandte Chemie-International Edition 51, 9339-9343 (2012).

$14 \mathrm{Li}, \mathrm{C}$. M. et al. Nickel-Gallium Intermetallic Nanocrystal Catalysts in the Semihydrogenation of Phenylacetylene. Chemcatchem 6, 824-831 (2014).

15 Zhou, H. R. et al. PdZn Intermetallic Nanostructure with Pd-Zn-Pd Ensembles for Highly Active and Chemoselective Semi-Hydrogenation of Acetylene. Acs Catalysis 6, 1054-1061 (2016).

16 Feng, Q. C. et al. Isolated Single-Atom Pd Sites in Intermetallic Nanostructures: High Catalytic Selectivity for Semihydrogenation of Alkynes. Journal of the American Chemical Society 139, 7294-7301 (2017).

17 Haubrich, J. et al. Adsorption of alpha,beta-Unsaturated Aldehydes on Pt(111) and Pt-Sn Alloys: II. Crotonaldehyde. Journal of Physical Chemistry C 113, 13947-13967 (2009).

18 Prinz, J. et al. Adsorption of Small Hydrocarbons on the Three-Fold PdGa Surfaces: The Road to Selective Hydrogenation. Journal of the American Chemical Society 136, $11792-$ 11798 (2014). 
19 Bradley, A. J. \& Thewlis, J. The structure of gamma-brass. Proceedings of the Royal Society of London Series A-Containing Papers of a Mathematical and Physical Character 112, 678-692 (1926).

20 Studt, F. et al. Identification of non-precious metal alloy catalysts for selective hydrogenation of acetylene. Science 320, 1320-1322 (2008).

21 Edstrom, V. A. \& Westman, S. X-ray Determination of Structure of Cubic Gamma Pd,Zn Phase. Acta Chemica Scandinavica 23, 279-285 (1969).

22 Connolly, J. W. D. \& Williams, A. R. Density-functional Theory Applied to Phase Transformations in Transition-metal Alloys. Physical Review B 27, 5169-5172 (1983).

23 Spanjers, C. S. et al. Determination of Bulk and Surface Atomic Arrangement in Ni-Zn gamma-Brass Phase at Different Ni to Zn Ratios. Chemistry of Materials 29, 504-512 (2017).

24 Huang, F. et al. Atomically Dispersed Pd on Nanodiamond/Graphene Hybrid for Selective Hydrogenation of Acetylene. Journal of the American Chemical Society 140, 13142-13146 (2018).

25 Gourdon, O. et al. Atomic distributions in the gamma-brass structure of the Cu-Zn system: A structural and theoretical study. Inorganic Chemistry 46, 251-260 (2007).

26 Spanjers, C. S. et al. Zinc inclusion to heterogeneous nickel catalysts reduces oligomerization during the semi-hydrogenation of acetylene. Journal of Catalysis 316, 164-173 (2014).

27 Vonheidenstam, O., Johansson, A. \& Westman, S. A Redetermination of Distribution of Atoms in $\mathrm{Cu}_{5} \mathrm{Zn}_{8}, \mathrm{Cu}_{5} \mathrm{Cd}_{8}$ and $\mathrm{Cu}_{9} \mathrm{Al}_{4}$. Acta Chemica Scandinavica 22, 653-661 (1968).

28 Larson, A. C. \& Dreele, R. B. V. General Structure Analysis System (GSAS) (Report LAUR 86-748). (Los Alamos National Laboratory, 2000).

29 Toby, B. H. EXPGUI, a graphical user interface for GSAS. Journal of Applied Crystallography 34, 210-213 (2001).

30 Kresse, G. \& Furthmuller, J. Efficiency of ab-initio total energy calculations for metals and semiconductors using a plane-wave basis set. Computational Materials Science 6, 15-50 (1996).

31 Kresse, G. \& Furthmuller, J. Efficient iterative schemes for ab initio total-energy calculations using a plane-wave basis set. Physical Review B 54, 11169-11186 (1996).

32 Kresse, G. \& Hafner, J. Ab Initio Molecular Dynamics for Liquid Metals. Physical Review $B$ 47, 558-561 (1993).

33 Perdew, J. P., Burke, K. \& Ernzerhof, M. Generalized gradient approximation made simple. Physical Review Letters 77, 3865-3868 (1996).

34 Methfessel, M. \& Paxton, A. T. High Precision Sampling for Brillouin Zone Integration in Metals. Physical Review B 40, 3616-3621 (1989).

35 Monkhorst, H. J. \& Pack, J. D. Special Points for Brillouin Zone Integrations. Physical Review B 13, 5188-5192 (1976).

36 Henkelman, G. \& Jonsson, H. Improved tangent estimate in the nudged elastic band method for finding minimum energy paths and saddle points. Journal of Chemical Physics 113, 9978-9985 (2000). 
Figures
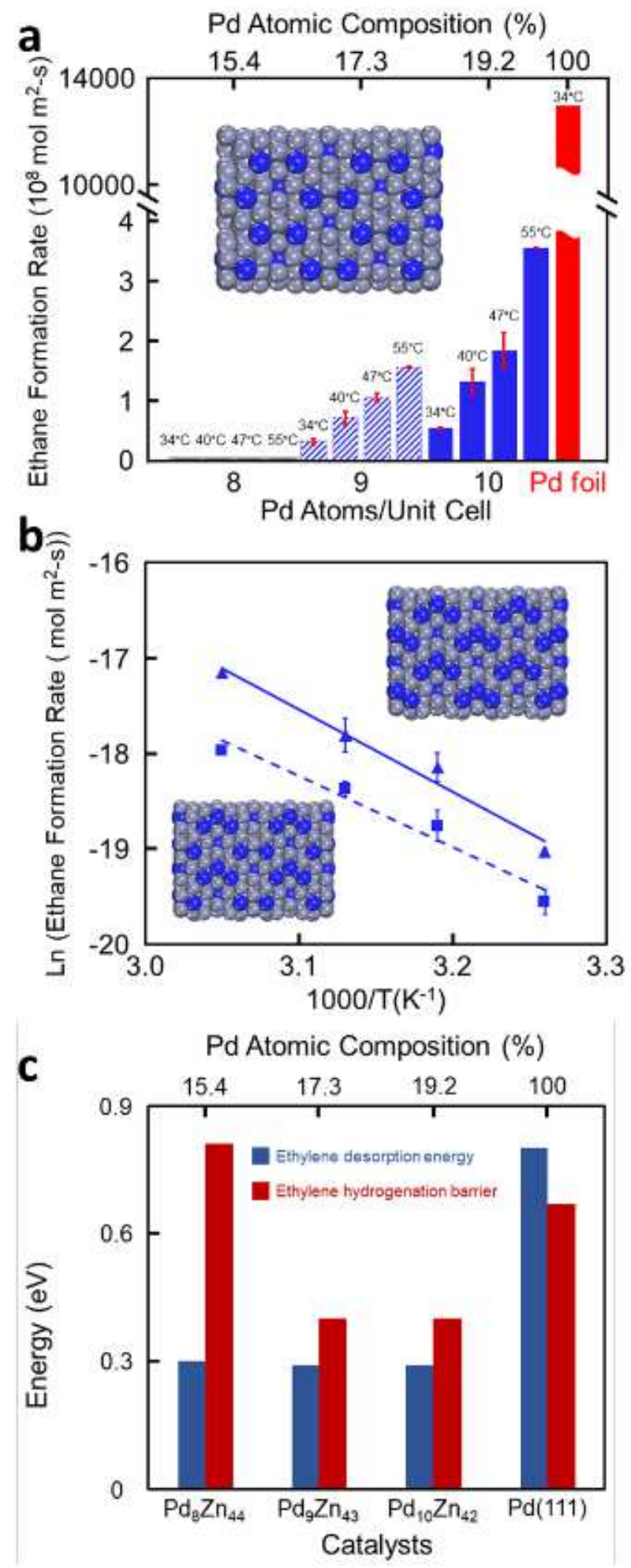

Figure 1

See manuscript for full figure caption. 

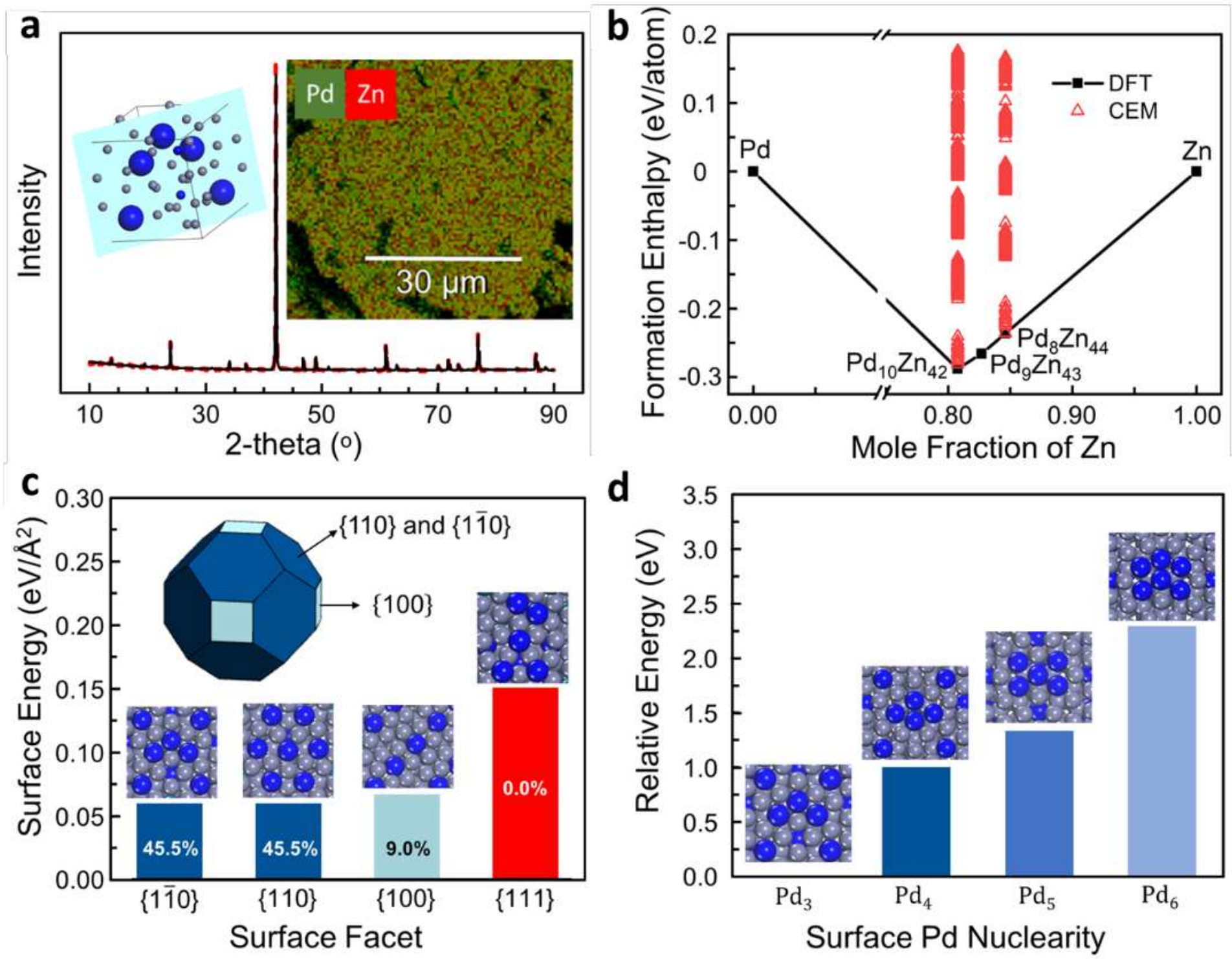

Figure 2

See manuscript for full figure caption. 

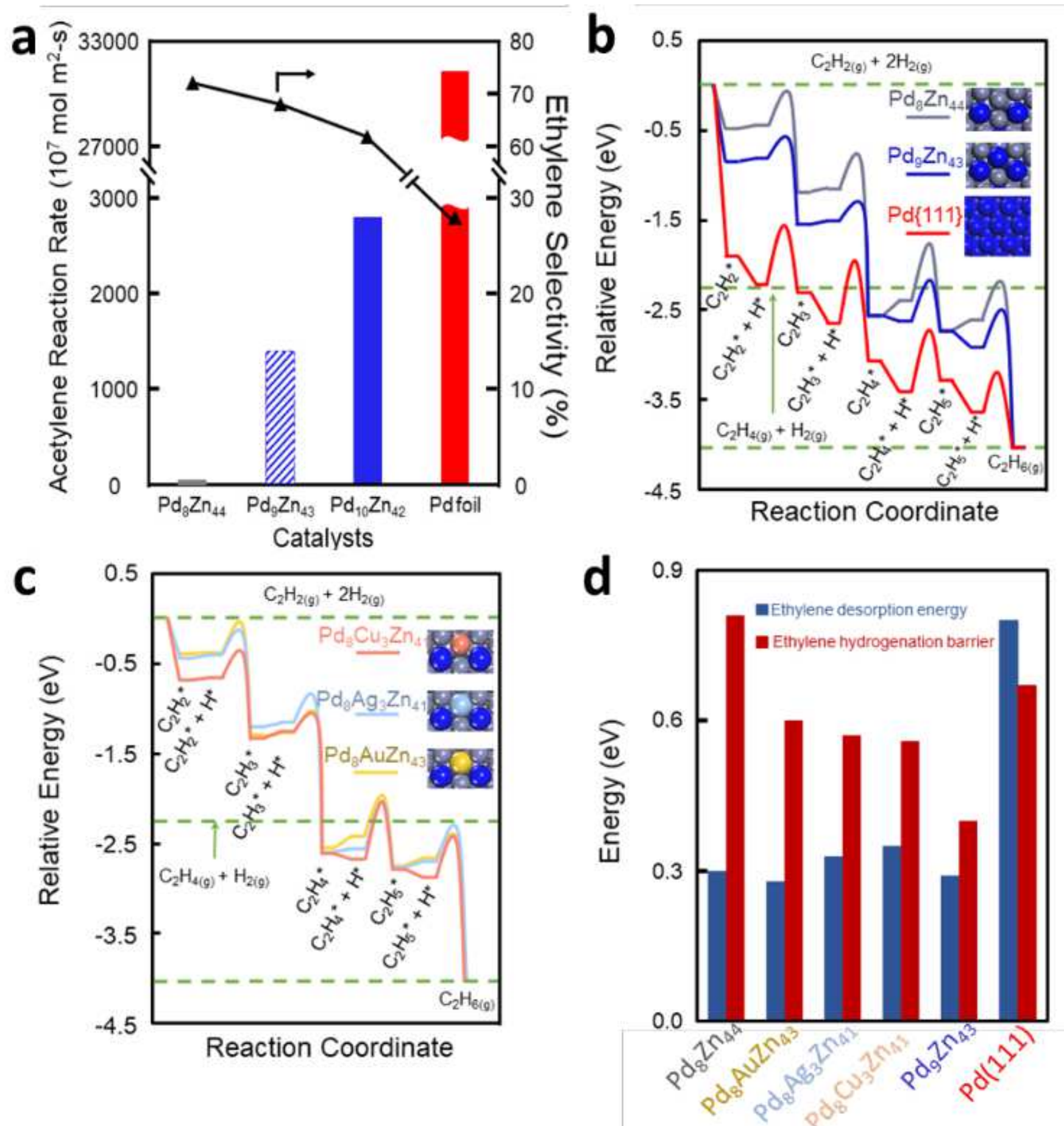

Figure 3

Experimental study of acetylene hydrogenation on Pd-Zn intermetallics and Pd foil and DFT reaction energy diagrams for acetylene hydrogenation on $\mathrm{Pd}-\mathrm{M}-\mathrm{Pd}(\mathrm{M}=\mathrm{Zn}, \mathrm{Pd}, \mathrm{Au}, \mathrm{Ag}, \mathrm{Cu})$ sites. (a) Acetylene hydrogenation results at $160^{\circ} \mathrm{C}$ using $\mathrm{C} 2 \mathrm{H} 2: \mathrm{H} 2=1: 100$. (b)-(c) Acetylene hydrogenation energy diagram on Pd-M-Pd. (d) Ethylene desorption energy and hydrogenation barrier on Pd-M-Pd. Structures with further details are presented in Table S6 and Figure S10. 


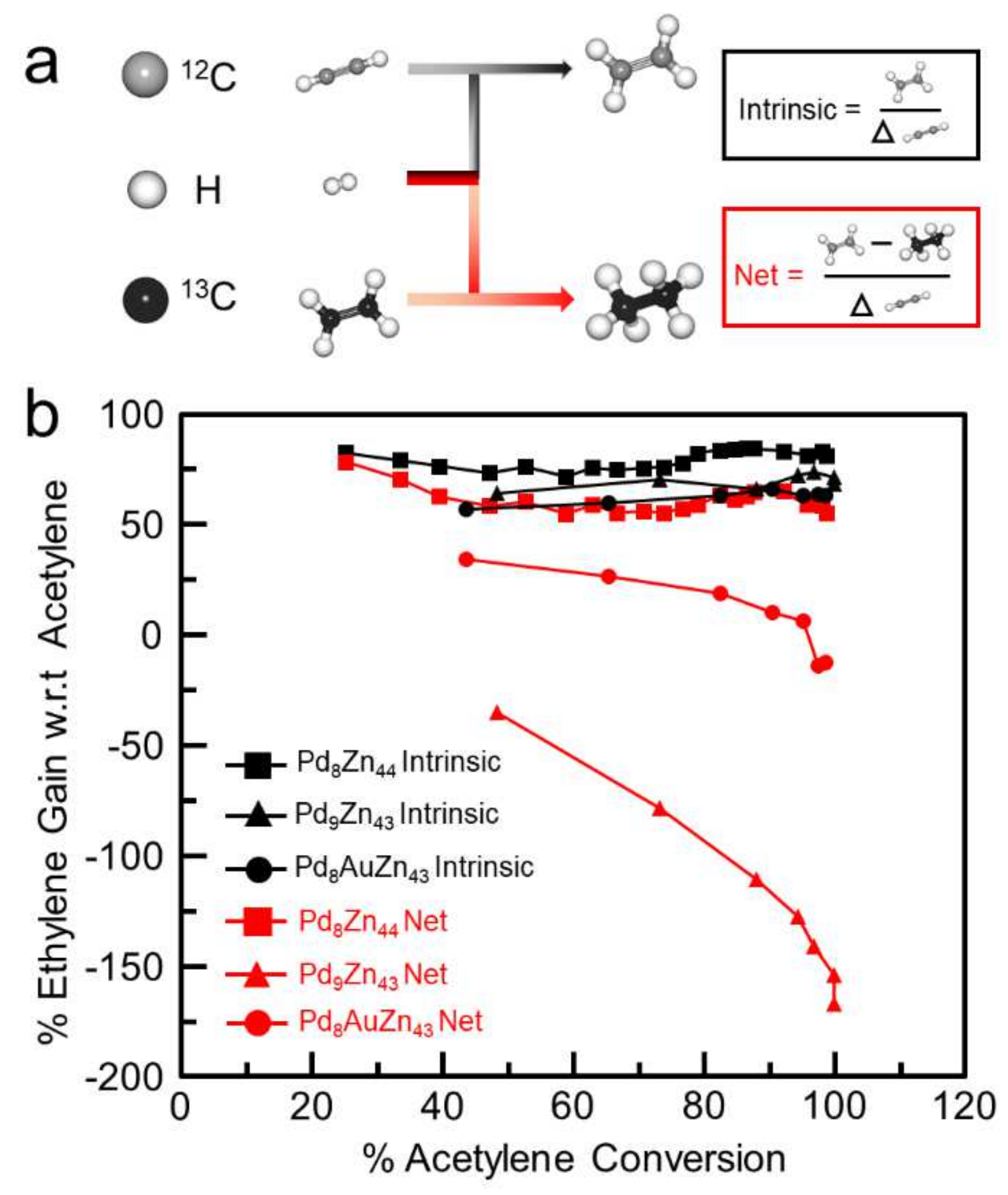

Figure 4

Competitive hydrogenation of 13C2-ethylene and 12C2-acetylene mixed feed over $\mathrm{y}$-brass [Pd, (Au) $\mathrm{Zn}$ ] catalysts. (a) 13C(black)2-ethylene and 12C(grey)2-acetylene reaction path and definition of intrinsic and net selectivity. Note the net selectivity can take on negative values if the rate of $13 \mathrm{C}$-ethylene hydrogenation is greater than the rate of $12 \mathrm{C}$-acetylene hydrogenation. (b) Net and intrinsic ethylene hydrogenation selectivity of Pd8Zn44 (red and black square, respectively), Pd9Zn43 (red and black 
triangle, respectively) and Pd8AuZn43 (red and black circle, respectively) at $160{ }^{\circ} \mathrm{C}, 12 \mathrm{C} 2 \mathrm{H} 2: 13 \mathrm{C} 2 \mathrm{H} 4: \mathrm{H} 2=$ 1:31:18.
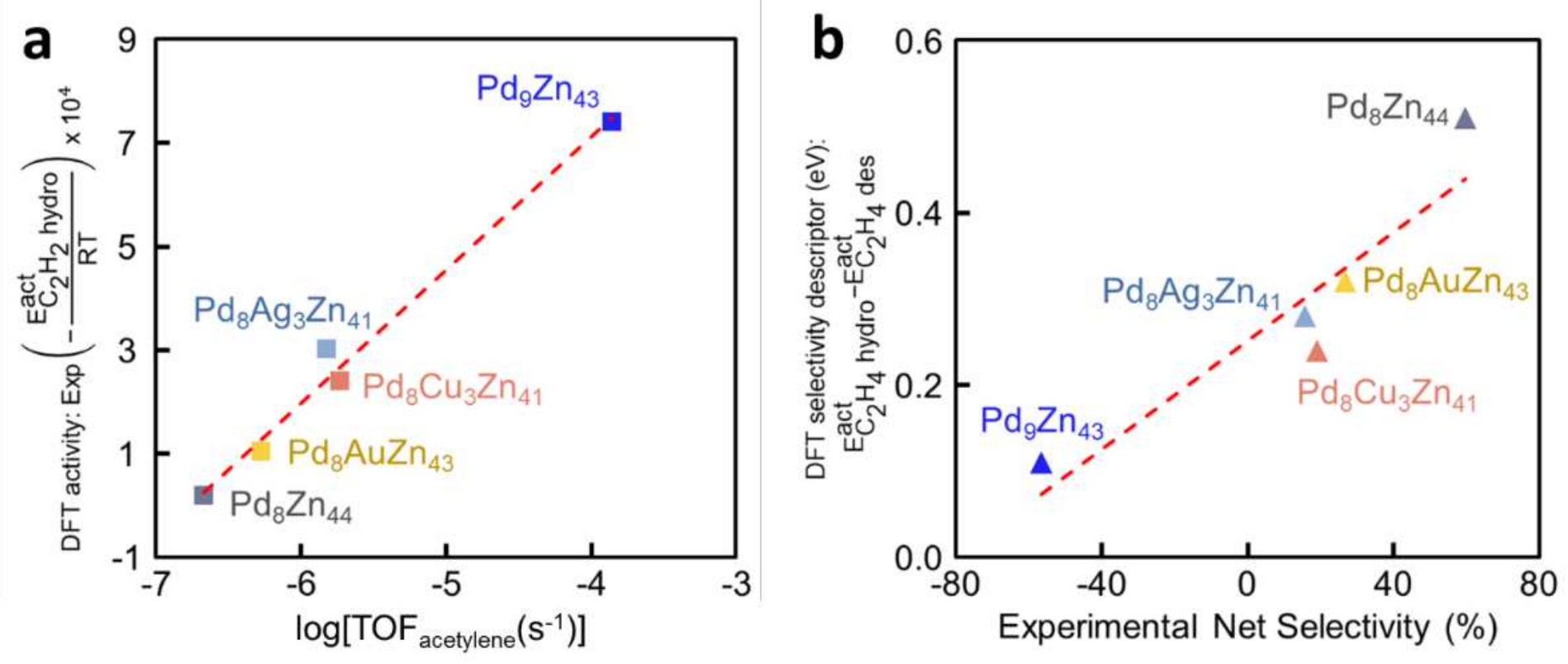

Figure 5

Experimental and computational comparison of acetylene semi-hydrogenation on $y$-brass [Pd, (M), Zn] (M $=\mathrm{Zn}, \mathrm{Pd}, \mathrm{Cu}, \mathrm{Ag}, \mathrm{Au})$. Qualitative agreement between experimental activity (a) and selectivity (b) with corresponding DFT descriptors to evaluate catalyst performance for acetylene semi-hydrogenation.

\section{Supplementary Files}

This is a list of supplementary files associated with this preprint. Click to download.

- PdZnintermetallicsNatureChemistrySIFINALsubmitted.pdf 